\title{
Contribution of the female reproductive tract to low fertility in postpartum lactating dairy cows
}

\author{
D. Rizos, ${ }^{*}$ F. Carter, $\uparrow$ U. Besenfelder, $\ddagger$ V. Havlicek, $\ddagger$ and P. Lonergan $\dagger^{1}$ \\ *Departamento de Reproducción Animal, Instituto Nacional de Investigación y Tecnología Agraria y Alimentaria (INIA), Madrid, Spain \\ †School of Agriculture, Food Science and Veterinary Medicine, College of Life Sciences, University College Dublin, Belfield, Dublin 4, Ireland \\ ‡Reproduction Centre-Wieselburg, University of Veterinary Medicine Vienna, Veterinärplatz 1, A-1210, Austria
}

\begin{abstract}
Infertility in dairy cattle is a multifactorial problem that may be linked to follicle development and the quality of the ovulated oocyte, to sperm transport and fertilization, to the reproductive tract environment, or to a combination of these factors. Using a stateof-the-art endoscopic embryo transfer technique, the aim of this study was to compare the ability of the reproductive tract of postpartum dairy cows and nulliparous heifers to support the development of early embryos to the blastocyst stage. Bovine embryos of 2 to 4 cells $(\mathrm{n}=1,800)$ were produced by in vitro maturation and fertilization of oocytes derived from the ovaries of slaughtered cattle. The estrus cycles of nulliparous Holstein heifers $(\mathrm{n}=10)$ and postpartum Holstein cows ( $\mathrm{n}=8$, approximately $60 \mathrm{~d}$ postpartum) were synchronized using an 8-d controlled internal drug release device coupled with prostaglandin injection. On d 2, one hundred 2- to 4-cell embryos were endoscopically transferred to the oviduct ipsilateral to the corpus luteum. Five days later, on d 7 , the oviduct and uterus were flushed nonsurgically to recover the embryos. The number of embryos developing to the blastocyst stage was recorded immediately at recovery and following overnight culture in vitro. A representative number of blastocysts from heifers and cows were stained to assess cell number. Progesterone concentrations were lower in cows than in heifers on $\mathrm{d} 5,6$, and 7 (d $7=$ $2.39 \pm 0.33$ vs. $5.34 \pm 0.77 \mathrm{ng} / \mathrm{mL}$, respectively). More embryos were recovered from heifers than cows $(79.0 \pm$ 7.0 vs. $57.2 \pm 11.4 \%$ ). Of the embryos recovered, $33.9 \pm$ $3.6 \%$ had developed to the blastocyst stage in the heifer oviduct compared with $18.3 \pm 7.9 \%$ in the postpartum cow oviduct. There was no evidence of a difference in blastocyst quality as evidenced by total cell number in the blastocysts $(71.2 \pm 5.7$ vs. $67.0 \pm 5.3$, respectively).
\end{abstract}

Received July 30, 2009.

Accepted November 23, 2009.

${ }^{1}$ Corresponding author: pat.lonergan@ucd.ie
In conclusion, the reproductive tract of the postpartum lactating dairy cow may be less capable of supporting early embryo development than that of the nonlactating heifer, and this may contribute to the lower conception rates observed in such animals.

Key words: oocyte, embryo, infertility, embryo transfer

\section{INTRODUCTION}

Low reproductive efficiency is a worldwide problem affecting the dairy industry and was the subject of recent reviews (Lucy, 2001; Leroy et al., 2008a,b). Although in some locations this situation is exacerbated by problems of heat stress in summer (Hansen, 2007), even in more moderate climates a steady decline in fertility has been noted. There is evidence of an association between high milk production and the lower conception rate observed in cows (25-40\%) compared with heifers (55-65\%; Pursley et al., 1997; Lucy, 2001).

Infertility in dairy cattle is a multifactorial problem that may be linked to suboptimal follicle development associated with reduced estrus exhibition and, consequently, low detection, suboptimal oocyte quality, altered sperm transport, problems at fertilization, a suboptimal reproductive tract environment to support embryo development, or a combination of these factors. One of the obstacles to achieving a better understanding of the causes of reduced fertility is the difficulty in identifying the respective contribution made by each of these factors.

One approach to understanding the causes of infertility or identifying at which stage problems arise has been to flush embryos at different stages after AI to determine fertilization failure and timing of embryonic mortality. Fertilization rate is very high in beef heifers (>90\%) and most embryonic mortality occurs by d 16 (Dunne et al., 2000). Sartori et al. (2002) compared lactating and nonlactating (either nulliparous heifers or dry cows) Holstein cattle in terms of fertilization rate and early embryo development after AI and found that fertilization was reduced only during summer in 
lactating dairy cows; however, lactating dairy cows had reduced embryo development compared with nonlactating females. This finding was confirmed by Leroy et al. (2005), suggesting that the ability of the reproductive tract to support normal embryo development may be impaired in lactating cows. Oocyte quality cannot be ruled out as a contributing factor because it is clear from in vitro fertilization (IVF) studies, where typically $80 \%$ of inseminated oocytes cleave and 30 to $40 \%$ develop to blastocysts, that fertilization success is no guarantee of future development.

One way of experimentally separating potential issues surrounding the follicle and oocyte from issues related to the reproductive tract environment is to use ovum pickup coupled with IVF. Although several authors reported development of ovum pickup-IVF embryos in dairy cows, few have compared development from dairy cows and heifers directly. Rizos et al. (2005) found no difference in the proportion of good-quality oocytes undergoing IVF and development to the blastocyst stage between lactating cows and heifers, whereas Snijders et al. (2000) observed that a lower proportion of oocytes recovered from dairy cows with a higher genetic merit for milk production underwent cleavage or developed to the blastocyst stage in vitro than those from cows of average genetic merit.

The use of embryo transfer allows the endogenous oocyte to be removed as a confounding factor and thus bypass the events of follicle development and oocyte quality. Conception rate was higher for embryo transfer (ET) than AI when fresh or frozen in vivo-produced embryos were used (Al-Katanani et al., 2002). Consistent with this, Demetrio et al. (2007) reported higher conception rates in lactating Brazilian dairy cows following the transfer of fresh embryos derived from nonlactating cows compared with after AI. In contrast, Sartori et al. (2006) compared ET with AI in dairy cows in Wisconsin at cooler times of the year and found no difference in conception rate.

The above studies involved routine ET at d 7 and tested only the ability of the reproductive tract to support development from d 7 onwards. None have examined the ability of the tract to support embryo development in the period encompassing the events between fertilization and $\mathrm{d} 7$. The reproductive tract environment undoubtedly plays a significant role in determining developmental outcome, as evidenced by the described role of progesterone in modifying endometrial gene expression (Satterfield et al., 2006; Forde et al., 2009) and the association of progesterone in the days immediately following conception with subsequent conceptus elongation (Mann and Lamming, 2001; Satterfield et al., 2006; Carter et al., 2008) and pregnancy rate (Stronge et al., 2005).
In this study, the hypothesis was that part of the difference in fertility between heifers and postpartum lactating dairy cows could be explained by differences in the ability of the reproductive tract (oviduct and uterus) to support early embryo development and that this would be related to circulating progesterone concentration. To test this hypothesis in single-ovulating animals would be extremely challenging because of the numbers of animals required. Therefore, using a stateof-the-art endoscopic transfer technique, we transferred 1,800 in vitro-produced embryos to the oviducts of nulliparous Holstein-Friesian heifers and postpartum lactating Holstein-Friesian cows and assessed their development to the blastocyst stage following recovery on $\mathrm{d} 7$.

\section{MATERIALS AND METHODS}

\section{In Vitro Production of Bovine Embryos}

Unless otherwise stated, all chemicals were purchased from Sigma Chemical Co. (Poole, UK). The techniques for producing embryos in vitro were described previously (Rizos et al., 2002). Immature cumulus oocyte complexes were obtained by aspirating follicles on bovine ovaries collected at slaughter. Cumulus oocyte complexes were matured for $24 \mathrm{~h}$ in TCM-199 medium supplemented with $10 \%$ (vol/vol) fetal calf serum (FCS) and $10 \mathrm{ng} / \mathrm{mL}$ of epidermal growth factor at $39^{\circ} \mathrm{C}$ under an atmosphere of $5 \% \mathrm{CO}_{2}$ in air with maximum humidity. For IVF, matured cumulus oocyte complexes were inseminated with frozen-thawed, Percoll-separated bull sperm at a concentration of $1 \times 10^{6}$ spermatozoa/ $\mathrm{mL}$. Gametes were coincubated at $39^{\circ} \mathrm{C}$ under an atmosphere of $5 \% \mathrm{CO}_{2}$ in air with maximum humidity.

At approximately $20 \mathrm{~h}$ post-insemination, presumptive zygotes were denuded, divided into groups of 40 to 50 , and transferred to $500-\mu \mathrm{L}$ culture wells. The basal medium for all embryo culture was synthetic oviduct fluid (SOF) supplemented with 5\% FCS. Cleavage rate was recorded at $48 \mathrm{~h}$ post-insemination and only cleaved embryos were used for transfer.

\section{Preparation of Recipient Animals and Embryo Transfer}

All experimental procedures involving animals were licensed by the Department of Health and Children (Dublin, Ireland), in accordance with the Cruelty to Animals Act (Ireland 1897) and European Community Directive 86/609/EC, and sanctioned by the University College Dublin Animals Research Ethics Committee.

The estrus cycles of nulliparous Holstein heifers (n $=10 ; \mathrm{BW}=349.1 \pm 12.21 \mathrm{~kg} ;$ age $=500 \pm 32 \mathrm{~d}$ ) and 


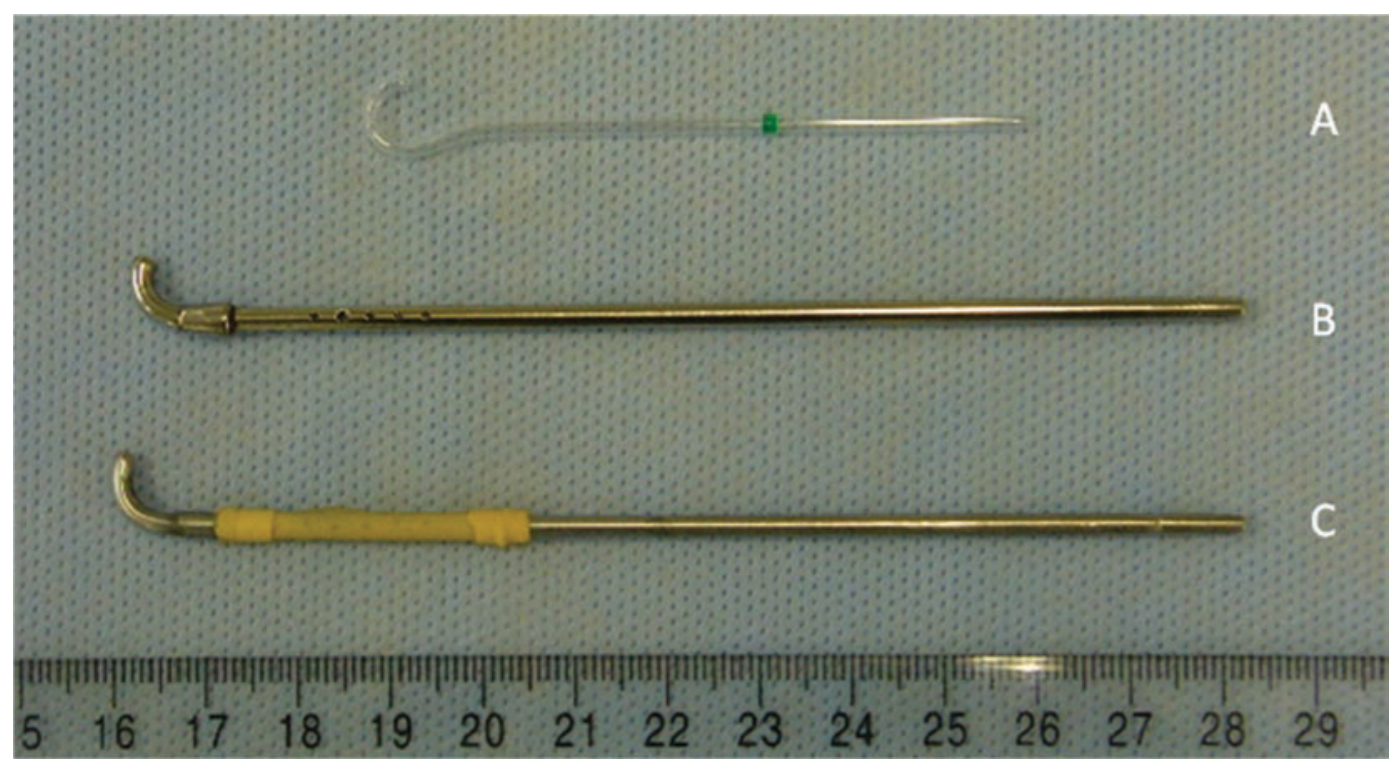

Figure 1. A) Fire-polished and curved 50- $\mu \mathrm{L}$ glass capillary, B) metal tube used to orient oviduct and initially locate the infundibulum, and C) silicon-covered flushing metal tube used for flushing any remaining embryos in the oviduct on $\mathrm{d} 7$ into the uterine horn before nonsurgical uterine flushing. Color version available in the online PDF.

postpartum lactating Holstein cows $(\mathrm{n}=8 ; 1$ second lactation, 7 third lactations; milk yield in previous lactation $=7,249 \pm 416 \mathrm{~kg} ; \mathrm{DIM}=59 \pm 2.51$ ) were synchronized using a controlled internal drug release device (InterAg, Hamilton, NZ) for 8 d. Two days before removal of the device, all animals received $15 \mathrm{mg}$ of a $\mathrm{PGF}_{2 \alpha}$ analog (Estrumate, Shering-Plough Animal Health, Hertfordshire, UK). All animals used were seen in estrus.

All animals were kept indoors for the duration of the experiment. Heifers were fed ad libitum grass silage supplemented with $50 \mathrm{~kg}$ of beet pulp nuts per tonne of silage at ensiling. Cows were fed ad libitum silage $(50 \%$ corn, $50 \%$ grass silage supplemented with $3 \mathrm{~kg}$ of corn protein balancer per head at feeding) plus a total of 8 $\mathrm{kg}$ of concentrate at milking.

Cleaved embryos produced in vitro were transferred ( $\mathrm{n}=100$ embryos per recipient) to the oviduct ipsilateral to the corpus luteum on d 2 of the estrus cycle as described previously (Havlicek et al., 2005). For transfer, recipients were restrained and received an epidural anesthesia (3.5 mL of $2 \%$ lidocaine solution, Selectavet, Weyarn-Holzolleng, Germany). The tip of a bitubular endoscopic set (Storz, Tuttlingen, Germany) containing the endoscope and the transfer system was placed in the peritoneal cavity via the fornix of the vagina. After passive air movement into the cavity, the reproductive organs were assessed for suitability for embryo transfer. The transfer system consisted of a 1-mL syringe embedded into a manual dosimeter (ivfetflex.com, Graz, Austria) and connected to a perfusion tube (no.
701908, Braun, Melsungen, Germany). A fire-polished and curved $50-\mu \mathrm{L}$ glass capillary (Brand, Wertheim, Germany) was attached to the end of the perfusion tube (Figure 1). Embryos were loaded in SOF into the tip of the glass capillary and transferred via the infundibulum into the ampulla (Figure 2).

Five days later, on $d 7$ of the estrus cycle, embryos were recovered by endoscopic flushing of the oviduct and uterine horns. Accessing the oviduct was performed as described above. The glass capillary used for transfer was replaced by a silicon-covered flushing metal tube (Figure 2). Forty to $60 \mathrm{~mL}$ of PBS supplemented with $1 \%$ FCS were flushed through the oviducts and uterine horns and collected via an embryo flushing catheter in an embryo filter (Em Con, no. 04135, Immuno Systems Inc., Spring Valley, WI). A further 300 to $400 \mathrm{~mL}$ was used for additional flushing of the uterine horns. Embryos were located under a stereo microscope. The number of embryos developing to the blastocyst stage was recorded immediately after recovery and following overnight culture in SOF medium. A representative number of blastocysts recovered from heifers $(\mathrm{n}=53$ blastocysts) and cows ( $\mathrm{n}=54$ blastocysts) were fixed in ethanol overnight and stained with Hoechst 33342 to assess cell number per blastocyst.

\section{Blood Sampling and Progesterone Assay}

Daily blood samples were collected from each animal from the day of estrus (d 0) until the day of embryo recovery (d 7) by jugular venipunture to assess pro- 

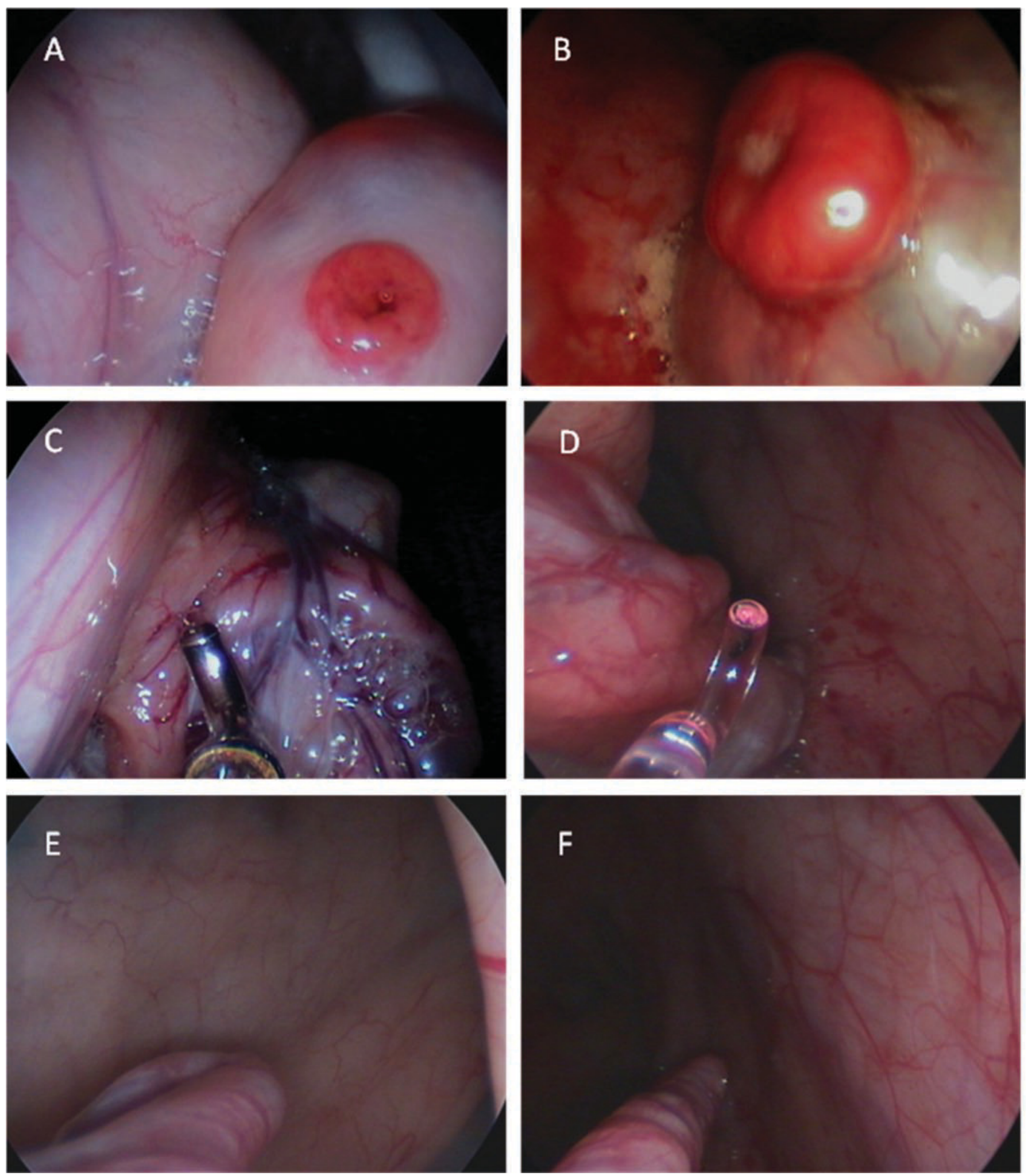

Figure 2. Representative endoscopic images of A) d 2 corpus luteum at time of transfer of embryos to the oviduct, B) d 7 corpus luteum at time of embryo recovery, C) metal tube used to orient oviduct and initially locate the infundibulum, D) fire-polished and curved 50- $\mu \mathrm{L}$ glass capillary containing embryos just before insertion into infundibulum, E) oviduct extended immediately after insertion of glass capillary, and $\mathrm{F}$ ) oviduct extended after pushing the pipette deep into the oviduct for deposition of the embryos. Color version available in the online PDF. 


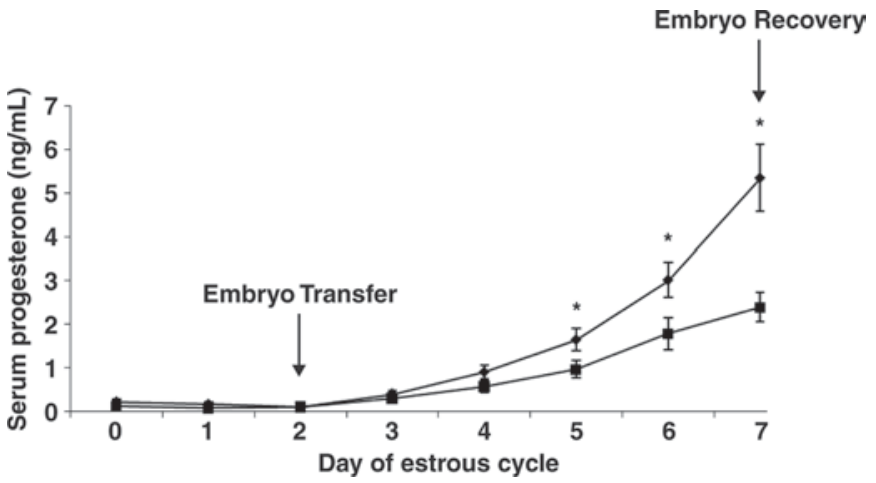

Figure 3. Mean $( \pm$ SEM $)$ serum progesterone concentration from d 0 (day of estrus) until d 7 (day of embryo recovery) in recipient Holstein heifers $(* \mathrm{n}=10)$ and postpartum lactating Holstein cows $(\boldsymbol{\square} ; \mathrm{n}=8)$. Using endoscopy, 100 in vitro-produced embryos were transferred to the oviduct ipsilateral to the corpus luteum of each animal on $\mathrm{d} 2(\mathrm{~d} 0=$ in vitro fertilization) and recovered by nonsurgical flushing of the oviduct and uterus on d 7. An asterisk indicates a significant difference $(P<0.05)$ between heifers and cows.

gesterone concentrations. Following collection, blood samples were refrigerated $\left(4^{\circ} \mathrm{C}\right)$ for 12 to $24 \mathrm{~h}$ before being centrifuged at $1,500 \times g$ at $4^{\circ} \mathrm{C}$ for $20 \mathrm{~min}$. Serum was separated and stored at $-20^{\circ} \mathrm{C}$ until assayed to determine progesterone concentration by time-resolved fluoroimmunoassay using an AutoDELFIA progesterone kit (Perkin Elmer, Wallac Oy, Turku, Finland). The sensitivity of the assay was $0.01 \mathrm{ng} / \mathrm{mL}$. The intraassay coefficients of variation were $4.6,5.5$, and $4.6 \%$ for high, medium, and low progesterone quality control sera, respectively.

\section{Statistical Analysis}

Mean progesterone concentrations between heifers and cows were compared on each day by Student's $t$-test. Data on recovery rate and the proportion of embryos developing to the blastocyst stage were compared with chi-squared analysis. Data on blastocyst cell number were compared by using Student's $t$-test. $P$-values $<0.05$ were considered significant.

\section{RESULTS}

On the day of embryo transfer, all animals displayed evidence of a fresh corpus luteum. One cow had a double ovulation. Mean progesterone concentrations were significantly higher in heifers than in lactating cows from d 5 to 7 (Figure 3 ). In addition, progesterone concentrations were higher between d 2 and 7 (i.e., the period when the embryos were present in the oviduct) in heifers than in cows $(1.94 \pm 0.25$ vs. $1.02 \pm 0.19 \mathrm{ng} /$ $\mathrm{mL}$, respectively).
More embryos were recovered from heifers than cows $(79.0 \pm 7.0$ vs. $57.2 \pm 11.4 \%, P<0.05$; Table 1$)$. Among the 10 heifers, the recovery rate was above $70 \%$ in all but 1 animal, where it was $21 \%$. In contrast, the recovery rate was more variable from cows; only in 3 of the 8 cows was the recovery rate above $70 \%$.

Of the putative embryos recovered, $27.9 \pm 3.1 \%$ had developed to the blastocyst stage in the heifer oviducts compared with $13.8 \pm 7.4 \%$ in the postpartum cow oviducts $(P<0.05$; Table 1$)$. Following overnight culture in vitro, these values increased to $33.9 \pm 3.6 \%$ and 18.3 $\pm 7.9 \%$ for heifers and postpartum cows, respectively $(P<0.05)$. Blastocysts were recovered from all heifers (range $=12.7-50.0 \%$ per animal). In contrast, in 2 of 8 cows no blastocysts were recovered. There was no evidence of a difference in blastocyst quality as evidenced by total cell number in the blastocysts $(71.2 \pm 5.7 \mathrm{vs}$. $67.0 \pm 5.3$, for heifers and cows, respectively).

\section{DISCUSSION}

This study provides evidence of impairment in the ability of the reproductive tract of the postpartum lactating dairy cow to support early embryo development. Several studies reported the outcome of embryo transfer at $\mathrm{d} 7$, thereby testing the ability of the reproductive tract to support development from d 7 onwards independent of the oocyte. This is the first study to examine the ability of the tract to support embryo development in the period encompassing the events between fertilization and $\mathrm{d} 7$ independent of the confounding factors potentially associated with the endogenous oocyte.

We chose to carry out the study at d 50 to 60 postpartum because this is the period when lactating dairy animals are normally being bred. Following parturition, in association with peak milk yield, high-yielding dairy cows enter a variable period of negative energy balance where the energy expenditure for peak milk production is not matched by the energy derived from DMI. The model of endoscopic oviduct transfer used in this study overcomes the potential deleterious effects on oocyte quality caused by exposure to an adverse follicular environment in association with the metabolic changes caused by negative energy balance and allows the reproductive tract capacity to be assessed independent of oocyte factors. In addition, this approach allows the transfer of large numbers of embryos in a way that would be practically very challenging using single embryo transfer.

Transferring early embryos to the oviduct is not new. Recently, refinement of minimally invasive endoscopic techniques has allowed unprecedented access to the oviducts of heifers and cows and allowed the study of 
the first few days of bovine embryo development in vivo in a manner previously not possible (Havlicek et al., 2005; Besenfelder et al., 2008). The high recovery rate obtained in dairy heifers in the current study (approximately $80 \%$ ) supports data in beef heifers (Tesfaye et al., 2007). The cause of the lower recovery rate from cows is unclear, but may be related to the larger size of the reproductive tract. The blastocyst formation rate in heifers of about 35\% was consistent with that expected using in vitro-derived embryos (Lonergan, 2007) and was consistent with previous data using the sheep oviduct, which indicated that culture in vivo can significantly alter blastocyst quality but does not improve blastocyst yield (Enright et al., 2000; Rizos et al., 2002). The observation in the present study that the cow oviduct and uterus were less capable of supporting development than that of heifers is somewhat surprising given that the sheep oviduct can support development and may suggest that, rather than simply lacking some constituents in the oviduct and uterine fluid, the environment was somewhat deleterious for the embryos.

Hasler (2006) reviewed data on embryo production following superstimulation in Holstein cattle and subsequent pregnancy rates following fresh embryo transfer into Holstein cows and heifers over a 20 - to 25 -yr period to determine whether the documented decline in fertility of dairy cows was accompanied by a corresponding decline in the efficacy of superovulation and embryo transfer. Little change was reported in either the mean number of transferable embryos resulting from superovulation (which could be interpreted as a proxy for oocyte quality) or in the proportion of recipient animals that became pregnant following embryo transfer, although heifers had a higher pregnancy rate than lactating cows. This would suggest that as milk yield had increased over the past several decades, the uterine capacity to support a pregnancy had not changed dramatically and would point to oocyte quality as a significant factor in the decline in dairy cow fertility. Consistent with this, Sartori et al. (2002) compared embryo quality on d 5 from normally ovulating, lactating vs. nonlactating dairy cows; although fertilization rate was similar (88-90\%), the proportion of viable embryos was much lower in lactating cows (53\%) than in nonlactating cows $(82 \%)$.

The lower progesterone concentration observed in cows compared with heifers supports previous data (Sartori et al., 2004; Wolfenson et al., 2004). High concentrations of circulating progesterone in the immediate postconception period were associated with an advancement of conceptus elongation (Satterfield et al., 2006; Carter et al., 2008) and higher pregnancy rates in cattle (Inskeep, 2004). Our previous data would suggest 
that elevated progesterone does not influence the proportion of oocytes reaching the blastocyst stage (Carter et al., 2008, Clemente et al., 2009). Yet, we did not examine the effect of low progesterone concentrations in vivo on development in those studies.

It has been hypothesized that increased milk production is associated with elevated steroid metabolism and increased liver blood flow (Wiltbank et al., 2006). Cows with higher milk production had a larger volume of luteal tissue but reduced circulating progesterone (Lopez et al., 2005). Sangsritavong et al. (2002) demonstrated that the metabolism of estrogen and progesterone was 2.3 times higher in lactating compared with nonlactating cows, and this could account for lower circulating concentrations.

The ability to separate the contribution of the embryo and the recipient to embryonic survival up to $\mathrm{d}$ 60 of pregnancy was developed in a model by McMillan (1998) that suggests that variation in recipient quality rather than embryo quality is a major source of variation in pregnancy rates after ET. Based on pregnancy rates after repeated ET, 2 herds were established (high and low pregnancy); significantly more embryos were elongated at d 14 in the high herd $(67 \%)$ than the low herd $(14 \%)$, and this delay was still apparent by $\mathrm{d} 17$, encompassing the critical window of maternal recognition of pregnancy.

In conclusion, the data presented indicated that the reproductive tract of the postpartum lactating dairy cow may be less capable of supporting development of the embryo than that of the nonlactating heifer and that this may be a consequence of the effect of lower circulating progesterone concentrations on the uterine environment. Future studies will examine potential differences in endometrial gene expression and histotroph composition between these 2 groups of animals.

\section{ACKNOWLEDGMENTS}

The authors thank M. Wade and P. Duffy (University College Dublin, Ireland) for excellent technical assistance and the staff at Kildare Chilling (Kildare, Ireland) and Kepak (Clonee, County Meath, Ireland) for allowing access to bovine tissues. This work was supported by Science Foundation Ireland under grant no. 07/SRC/B1156 (the opinions, findings, and conclusions or recommendations expressed in this material are those of the authors and do not necessarily reflect the views of the Science Foundation Ireland). D. Rizos was supported by a grant from the Spanish Ministry for Science and Innovation (AGL2009-11810).

\section{REFERENCES}

Al-Katanani, Y. M., M. Drost, R. L. Monson, J. J. Rutledge, C. E. Krininger 3rd, J. Block, W. W. Thatcher, and P. J. Hansen. 2002. Pregnancy rates following timed embryo transfer with fresh or vitrified in vitro produced embryos in lactating dairy cows under heat stress conditions. Theriogenology 58:171-182.

Besenfelder, U., V. Havlicek, G. Moesslacher, M. Gilles, D. Tesfaye, J. Griese, M. Hoelker, P. M. Hyttel, J. Laurincik, G. Brem, and K. Schellander. 2008. Endoscopic recovery of early preimplantation bovine embryos: Effect of hormonal stimulation, embryo kinetics and repeated collection. Reprod. Domest. Anim. 43:566-572.

Carter, F., N. Forde, P. Duffy, M. Wade, T. Fair, M. A. Crowe, A. C Evans, D. A. Kenny, J. F. Roche, and P. Lonergan. 2008. Effect of increasing progesterone concentration from Day 3 of pregnancy on subsequent embryo survival and development in beef heifers. Reprod. Fertil. Dev. 20:368-375.

Clemente, M., J. de La Fuente, T. Fair, A. Al Naib, A. GutierrezAdan, J. Roche, D. Rizos, and P. Lonergan. 2009. Progesterone and conceptus elongation in cattle: A direct effect on the embryo or an indirect effect via the endometrium? Reproduction 138:507-517.

Demetrio, D. G., R. M. Santos, C. G. Demetrio, and J. L. Vasconcelos. 2007. Factors affecting conception rates following artificial insemination or embryo transfer in lactating Holstein cows. J. Dairy Sci. 90:5073-5082.

Dunne, L. D., M. G. Diskin, and J. M. Sreenan. 2000. Embryo and foetal loss in beef heifers between day 14 of gestation and full term. Anim. Reprod. Sci. 58:39-44.

Enright, B. P., P. Lonergan, A. Dinnyes, T. Fair, F. A. Ward, X Yang, and M. P. Boland. 2000. Culture of in vitro produced bovine zygotes in vitro vs in vivo: Implications for early embryo development and quality. Theriogenology 54:659-673.

Forde, N., F. Carter, T. Fair, M. A. Crowe, A. C. O. Evans, T. E Spencer, F. W. Bazer, R. McBride, M. P. Boland, P. O'Gaora, P. Lonergan, and J. F. Roche. 2009. Progesterone-regulated changes in endometrial gene expression contribute to advanced conceptus development in cattle. Biol. Reprod. 81:784-794.

Hansen, P. J. 2007. Exploitation of genetic and physiological determinants of embryonic resistance to elevated temperature to improve embryonic survival in dairy cattle during heat stress. Theriogenology 68(Suppl. 1):S242-S249.

Hasler, J. F. 2006. The Holstein cow in embryo transfer today as compared to 20 years ago. Theriogenology 65:4-16.

Havlicek, V., F. Wetscher, T. Huber, G. Brem, M. Mueller, and U. Besenfelder. 2005. In vivo culture of IVM/IVF embryos in bovine oviducts by transvaginal endoscopy. J. Vet. Med. A Physiol. Pathol. Clin. Med. 52:94-98.

Inskeep, E. K. 2004. Preovulatory, postovulatory, and postmaternal recognition effects of concentrations of progesterone on embryonic survival in the cow. J. Anim. Sci. 82(E-Suppl.):E24-E39.

Leroy, J. L., G. Opsomer, S. De Vliegher, T. Vanholder, L. Goossens, A. Geldhof, P. E. Bols, A. de Kruif, and A. Van Soom. 2005 Comparison of embryo quality in high-yielding dairy cows, in dairy heifers and in beef cows. Theriogenology 64:2022-2036.

Leroy, J. L., G. Opsomer, A. Van Soom, I. G. Goovaerts, and P. E. Bols. 2008a. Reduced fertility in high-yielding dairy cows: Are the oocyte and embryo in danger? Part I. The importance of negative energy balance and altered corpus luteum function to the reduction of oocyte and embryo quality in high-yielding dairy cows. Reprod. Domest. Anim. 43:612-622.

Leroy, J. L., A. Van Soom, G. Opsomer, I. G. Goovaerts, and P. E. Bols. 2008b. Reduced fertility in high-yielding dairy cows: Are the oocyte and embryo in danger? Part II. Mechanisms linking nutrition and reduced oocyte and embryo quality in high-yielding dairy cows. Reprod. Domest. Anim. 43:623-632.

Lonergan, P. 2007. State-of-the-art embryo technologies in cattle. Soc. Reprod. Fertil. Suppl. 64:315-325. 
Lopez, H., D. Z. Caraviello, L. D. Satter, P. M. Fricke, and M. C. Wiltbank. 2005. Relationship between level of milk production and multiple ovulations in lactating dairy cows. J. Dairy Sci. 88:2783-2793.

Lucy, M. C. 2001. Reproductive loss in high-producing dairy cattle: Where will it end? J. Dairy Sci. 84:1277-1293.

Mann, G. E., and G. E. Lamming. 2001. Relationship between maternal endocrine environment, early embryo development and inhibition of the luteolytic mechanism in cows. Reproduction 121:175-180.

McMillan, W. H. 1998. Statistical models predicting embryo survival to term in cattle after embryo transfer. Theriogenology 50:10531070.

Pursley, J. R., M. C. Wiltbank, J. S. Stevenson, J. S. Ottobre, H. A. Garverick, and L. L. Anderson. 1997. Pregnancy rates per artificial insemination for cows and heifers inseminated at a synchronized ovulation or synchronized estrus. J. Dairy Sci. 80:295-300.

Rizos, D., L. Burke, P. Duffy, M. Wade, J. F. Mee, K. J. O'Farrell, M. MacSiurtain, M. P. Boland, and P. Lonergan. 2005. Comparisons between nulliparous heifers and cows as oocyte donors for embryo production in vitro. Theriogenology 63:939-949.

Rizos, D., F. Ward, P. Duffy, M. P. Boland, and P. Lonergan. 2002. Consequences of bovine oocyte maturation, fertilization or early embryo development in vitro versus in vivo: Implications for blastocyst yield and blastocyst quality. Mol. Reprod. Dev. $61: 234-248$.

Sangsritavong, S., D. K. Combs, R. Sartori, L. E. Armentano, and M. C. Wiltbank. 2002. High feed intake increases liver blood flow and metabolism of progesterone and estradiol-17beta in dairy cattle. J. Dairy Sci. 85:2831-2842.

Sartori, R., A. Gumen, J. N. Guenther, A. H. Souza, D. Z. Caraviello, and M. C. Wiltbank. 2006. Comparison of artificial insemination versus embryo transfer in lactating dairy cows. Theriogenology 65:1311-1321.
Sartori, R., J. M. Haughian, R. D. Shaver, G. J. Rosa, and M. C. Wiltbank. 2004. Comparison of ovarian function and circulating steroids in estrous cycles of Holstein heifers and lactating cows. J. Dairy Sci. 87:905-920.

Sartori, R., R. Sartor-Bergfelt, S. A. Mertens, J. N. Guenther, J. J. Parrish, and M. C. Wiltbank. 2002. Fertilization and early embryonic development in heifers and lactating cows in summer and lactating and dry cows in winter. J. Dairy Sci. 85:28032812 .

Satterfield, M. C., F. W. Bazer, and T. E. Spencer. 2006. Progesterone regulation of preimplantation conceptus growth and galectin 15 (LGALS15) in the ovine uterus. Biol. Reprod. 75:289-296.

Snijders, S. E., P. Dillon, D. O'Callaghan, and M. P. Boland. 2000. Effect of genetic merit, milk yield, body condition and lactation number on in vitro oocyte development in dairy cows. Theriogenology 53:981-989.

Stronge, A. J., J. M. Sreenan, M. G. Diskin, J. F. Mee, D. A. Kenny, and D. G. Morris. 2005. Post-insemination milk progesterone concentration and embryo survival in dairy cows. Theriogenology 64:1212-1224.

Tesfaye, D., P. Lonergan, M. Hoelker, F. Rings, K. Nganvongpanit, V. Havlicek, U. Besenfelder, D. Jennen, E. Tholen, and K. Schellander. 2007. Suppression of connexin 43 and E-cadherin transcripts in in vitro derived bovine embryos following culture in vitro or in vivo in the homologous bovine oviduct. Mol. Reprod. Dev. 74:978-988.

Wiltbank, M., H. Lopez, R. Sartori, S. Sangsritavong, and A. Gumen. 2006. Changes in reproductive physiology of lactating dairy cows due to elevated steroid metabolism. Theriogenology 65:17-29.

Wolfenson, D., G. Inbar, Z. Roth, M. Kaim, A. Bloch, and R. BrawTal. 2004. Follicular dynamics and concentrations of steroids and gonadotropins in lactating cows and nulliparous heifers. Theriogenology 15:1042-1055. 